\title{
A percepção dos agentes comunitários de saúde nos traumatismos dentários: retrato de um município baiano
}

\author{
The Perception of Community Health Agents in Dental Trauma: \\ a Portrait of a Bahia Municipality
}

\author{
Indiara Moraes Santos ${ }^{1}$ \\ Suélem Maria Santana Pinheiro Ferreira² \\ Talise Batista de Jesus Sales ${ }^{1}$ \\ Ana LUIZA Rodrigues Garcia ${ }^{1}$ \\ Renato Pial Pereira ${ }^{3}$ \\ RogérIo VIEIRA SILVA
}

\begin{abstract}
RESUMO
Objetivo: Avaliar os conhecimentos sobre Traumatismos Dentários (TD) dos Agentes Comunitários de Saúde (ACS) da Atenção Básica do município de Vitória da Conquista na Bahia.

Métodos: Estudo transversal com 156 ACS vinculados à atenção básica da zona urbana de Vitória da Conquista (BA). Realizou-se a coleta de dados por meio de um formulário abrangendo os conhecimentos dos ACS sobre o TD. Os dados foram tabulados e analisados por intermédio do SPSS, obtendo-se frequências absolutas e relativas. Resultados: Os ACS participaram do curso introdutório (86,5\%), porém o TD não foi abordado (73,1\%). Quanto à atitude dos ACS frente ao TD, $81,4 \%$ afirmaram que não utilizam qualquer protocolo de atendimento. Em casos de avulsão, 76,3\% asseveraram que somente o CD poderia realizar o reimplante dentário, sendo a orientação armazenar o dente em água filtrada e fervida $(25 \%)$. Quanto às fraturas, $5,8 \%$ acreditam que o fragmento dentário não teria mais utilidade. Dos ACS, $98,1 \%$ acham importante ter os conhecimentos acerca do TD para orientar a população.

Conclusão: A maioria dos ACS não tem conhecimentos sobre o TD e eles não se sentem seguros para orientar a comunidade e ainda não estão preparados para o pronto atendimento.

Palavras-chave: Agentes Comunitários de Saúde. Conhecimentos, Atitudes e Prática em Saúde. Traumatismos DENTÁRIOS.
\end{abstract}

\begin{abstract}
Objective: To evaluate the knowledge about Dental Injuries (TD) of the Community Health Agents (ACS) of Basic Care of Vitória da Conquista, Brazil.

Methods: A cross-sectional study with 156 ACS linked to primary care in the urban area of Vitória da Conquista (BA). Data collection was done through a comprehensive form on ACS knowledge about TD. The data were tabulated and analyzed through the SPSS, obtaining absolute and related frequencies.

Results: The ACS participated in the introductory course (86.5\%), but not TDT (73.1\%). Regarding an ACS attitude towards TD, $81.4 \%$ is not available in the care protocol. In cases of avulsion, $76.3 \%$ stated that they are available, and can perform the dental reimplantation, being a stored environment or tooth in filtered and boiled water (25\%). As for fractures, $5.8 \%$ believe that the dental fragment is no longer useful. $98.1 \%$ of CHWs find it important to know about TD to guide the population.

Conclusion: Most ACS have no knowledge about TD and do not feel safe to guide a community and are not yet prepared for care.

Key-words: Community Health Agents. Knowledge, Attitudes and Practice in Health. Dental Injuries.

\footnotetext{
${ }^{1}$ Graduada em Odontologia. Faculdade Independente do Nordeste - FAINOR.

${ }^{2}$ Mestre e Doutoranda em Saúde Pública - Instituto de Saúde Coletiva/Universidade Federal da Bahia(ISC-UFBA). Docente da Universidade do Estado da Bahia (UNEB).

${ }^{3}$ Mestre em Endodontia - SL Mandic (SP). Universidade Estadual do Sudoeste da Bahia.

${ }^{4}$ Mestre e Doutor em Endodontia - Pontifícia Universidade Católica/Minas Gerais (PUC-MG). Docente da FAINOR
} 


\section{INTRODUÇÃO}

O traumatismo dentário (TD) é classificado como um problema de saúde pública e possui alta prevalência. $O$ trauma na região bucal engloba $5 \%$ de todas as lesões que as pessoas procuram tratamento, geralmente acomete crianças em idade escolar, podendo também incidir em faixas etárias envolvidas em esportes, violência, acidentes de trânsito, lazer, inclusive os idosos que já estão propícios a quedas. Além de ter alto custo, necessita de equipe multiprofissional e acompanhamento durante toda a vida. Ademais, o traumatismo pode levar a perdas dentárias que são muitas vezes irrecuperáveis, o que torna relevante a avaliação desse agravo por meio de inquéritos epidemiológicos que possibilitam planejar ações estratégicas para diminuir suas causas. ${ }^{1}$

Os inquéritos epidemiológicos em saúde bucal são ferramentas importantes e úteis, pois traçam um perfil das condições de saúde bucal da população brasileira. Até o momento já foram realizados quatro inquéritos em 1986, 1996, 2003 e 2010. Apesar de ter representado um expressivo avanço nos dois primeiros, o SBBrasil 2003 mostrou algumas deficiências, com perda de dados importantes. Para explicar, quando um indivíduo que apresentasse cárie e trauma em um mesmo elemento dentário, a informação cárie prevalecia e acontecia da mesma forma quando um dente era perdido. Em relação à fratura dentária, independente da extensão de envolvimento dos tecidos dentários, codificou-se do mesmo modo, não sendo registrada a gravidade do traumatismo. ${ }^{2}$

O Ministério da Saúde (MS), por intermédio da Coordenação Nacional de Saúde Bucal, concluiu, em 2011, o mais recente inquérito epidemiológico denominado SBBrasil 2010, que representou um marco na epidemiologia no Brasil sobre o tema, pois pela primeira vez os dados de traumatismos dentários vieram de uma forma independente e separada, além de ampliar e aprofundar os dados registrados no SBBrasil 2003 e proporcionou um diagnóstico mais completo da condição de saúde bucal do país, pois se tem dados coletados nas cinco regiões do Brasil. ${ }^{2}$ Porém, além dos aspectos positivos exibidos, ainda existem desafios para a avaliação da saúde bucal do país a serem considerados em experimentos futuros. ${ }^{3}$

À vista disso, deve-se avaliar os tipos de lesões traumáticas que vão desde uma trinca de esmalte até a avulsão do dente do seu alvéolo, podendo envolver a mucosa bucal, osso alveolar, estruturas dento-alveolares relacionadas e a face do paciente. ${ }^{4}$ Isso representa uma condição de urgência, portanto $\mathrm{o}$ pronto atendimento que, muitas vezes, fica comprometido pela dificuldade do manejo técnico do Cirurgião-Dentista (CD), falta de conhecimento da população e medo do paciente em relação ao atendimento, o que pode levar com frequência a um prognóstico duvidoso, sombrio em relação ao caso clínico. ${ }^{5}$

Partindo desses pressupostos, é necessário sensibilizar a população, profissionais de saúde e implementar atividades de educação em saúde bucal no âmbito público e privado para aumentar a chance de sucesso do tratamento. Nesse contexto, o Agente Comunitário de Saúde (ACS) representa um profissional peçachave na atenção básica e, em especial, na Estratégia de Saúde da Família (ESF) para instruir a comunidade sobre as manobras que devem ser realizadas. ${ }^{5}$ Para isso, antes mesmo da criação da ESF, em 1991 o Ministério da Saúde implantou o Programa de Agentes Comunitários da Saúde (PACS) para possibilitar o entendimento ampliado dos profissionais da equipe sobre o processo saúdeldoença e para que estes estejam cientes da necessidade de agir preventivamente. Porém, as ações de saúde bucal ficam para segundo plano e muitas vezes não fazem parte do processo de educação permanente. ${ }^{6}$ 
No entanto, os ACS assumem importante papel frente aos TD, por serem os profissionais que formam elos entre a população e a atenção básica de saúde, dispondo-se como mediadores de informações obtidas da equipe de saúde e da comunidade. Desse modo, a realidade local é transmitida para os profissionais da equipe de saúde, proporcionando uma melhoria na qualidade dos tratamentos e redução das necessidades de consultas de urgências, aprimorando ainda as condições de vida da população. ${ }^{5}$ Para isso, vale ressaltar a importância dos gestores do Sistema Único de Saúde (SUS) no investimento para o processo de educação permanente desses profissionais, necessário para que os mesmos estejam atualizados quanto às suas atribuições e capacitados a promover saúde. ${ }^{7}$

Além disso, a relação estabelecida pelo contato direto dos ACS com a população facilita o processo de educação popular em saúde, a criação do vínculo e confiança, sendo de fundamental importância que esses profissionais adquiram os conhecimentos necessários sobre o TD para instruir a comunidade, contribuindo com uma atuação mais completa e integral. Dessa forma, os ACS com os demais membros da equipe, na busca da integralidade do atendimento, precisam abordar as questões relacionadas à saúde bucal, e o TD merece destaque. ${ }^{7}$

Diante do exposto, o presente estudo teve como objetivo avaliar os conhecimentos dos ACS da zona urbana, que trabalham na atenção básica em um município de médio porte na Bahia, sobre os traumatismos dentários.

\section{MATERIAIS E MÉtodos}

Previamente à coleta de dados, o estudo foi apresentado e aprovado pelo Comitê de Ética e Pesquisa (CEP) da Faculdade Independente do Nordeste, sob parecer 1.834.124|2016. Em seguida, foi encaminhado e aprovado pelo Polo de Educação permanente da Secretaria Municipal de Saúde de Vitória da Conquista para então proceder com a realização da coleta de dados nas unidades básicas do município, dessa forma, seguiram-se os princípios éticos e legais da pesquisa.

Após aprovação do CEP, sorteou-se uma USF que continha 19 ACS, na qual foi realizado um estudo piloto, com o objetivo de calibrar as entrevistadoras, esclarecer possíveis falhas el ou falta de clareza no instrumento de coleta e tentar ajustá-las em tempo hábil para não comprometer o estudo, bem como, minimizar possíveis vieses. Nesse momento, participaram 15 ACS, dois não aceitaram participar do estudo e dois se encontravam de férias.

Para a realização da coleta de dados, efetuou-se cálculo amostral, por meio de análises estatísticas, para a obtenção do número de indivíduos participantes, no qual se definiu que o critério para a seleção da amostra seria probabilístico por conglomerado. O estabelecimento do tamanho amostral se deu por intermédio da estimativa de proporções ${ }^{9}$ com nível de confiança 95\% e erro permissível de $10 \%$. A partir da busca por várias estimativas e ausência de parâmetros conhecidos na literatura, optou-se por utilizar como referência a proporção 0,5 , de forma a maximizar o tamanho amostral. Com base nesses critérios, obteve-se tamanho amostral de 156 ACS.

À partir dessa análise preliminar, realizou-se um estudo de corte transversal descritivo, com os 156 ACS vinculados às Unidades de Saúde da atenção básica da zona urbana do município de Vitória da Conquista, Bahia, Brasil. Essa cidade está localizada $509 \mathrm{~km}$ distante da capital, sendo considerada a terceira maior cidade do Estado, com cerca de 348.718 mil habitantes conforme o IBGE em 2017. ${ }^{8}$ A atenção básica da zona urbana de Vitória da Conquista conta com 14 Unidades de Saúde da Família (USF) e oito Unidades Básica de Saúde (UBS), nas 
quais fazem parte das equipes da zona urbana do município 375 ACS, sendo distribuídos 139 em UBS e 236 em USF.

A amostra foi selecionada por amostragem de conglomerado de três estágios, na qual foram sorteadas primeiramente dez unidades de saúde, sendo oito USF e duas UBS que atenderam aos critérios de inclusão preestabelecidos do estudo (profissionais atuantes na zona urbana, ter no mínimo seis meses de atuação na unidade e aceitar participar da pesquisa mediante TCLE), os profissionais que não se enquadravam nos critérios de inclusão foram excluídos da amostra (ACS que trabalham na zona rural, profissionais afastados de suas atividades por algum motivo, recém-contratados ou transferidos com até seis meses de trabalho). Então, realizou-se o segundo e o terceiro sorteio respectivamente. A coleta dos dados foi finalizada no mês de dezembro de 2016, totalizando-se dez USF's e três UBS's.

A coleta de dados se fez por meio da aplicação de um formulário de pesquisa sob a forma de entrevista direta. Continha 37 questões objetivas, de linguagem clara, adequada à categoria profissional, sobre identificação do ACS, expectativas/satisfação do profissional no trabalho executado na atenção básica, atitudes dos ACS frente aos TD e condutas no pronto atendimento que foram dirigidas aos ACS por três entrevistadoras sem que houvesse alteração da pergunta e/ou influência a respeito da resposta do entrevistado pelas entrevistadoras, pois estas realizaram o preenchimento do instrumento de coleta.

Após coletados, os dados foram organizados em um banco de dados e analisados por meio do software R, versão 3.2.2. Em seguida, foi realizada a análise estatística descritiva, e envolveu a obtenção de frequências absolutas e relativas, para as variáveis qualitativas, do mesmo modo, medidas de tendência central e dispersão para as variáveis quantitativas.

\section{Resultados}

A partir deste estudo com 156 ACS, distribuídos em 13 unidades de saúde, obtevese que $70,5 \%$ trabalham em Unidade de Saúde da Família e 29,5\% em Unidade Básica de Saúde. A maior parte era do gênero feminino $(91,7 \%)$, raça/cor parda autodeclarados $(64,1 \%)$. Em relação ao nível de escolaridade, a maioria dos entrevistados tinha ensino médio completo $(69,9 \%)$ (Tabela 1$)$.

Tabela 1. Perfil dos Agentes Comunitários de Saúde (ACS) inseridos na Atenção Básica da zona urbana de Vitória da Conquista (BA), Brasil, 2017.

\begin{tabular}{|c|c|c|c|}
\hline \multicolumn{2}{|l|}{ Variáveis } & N. & $\%$ \\
\hline \multirow{2}{*}{$\begin{array}{c}\text { Tipo de } \\
\text { estabelecimento } \\
(n=156)\end{array}$} & $\begin{array}{l}\text { Unidade Básica de } \\
\text { Saúde }\end{array}$ & 46 & 29,5 \\
\hline & $\begin{array}{c}\text { Unidade de Saúde } \\
\text { da Família }\end{array}$ & 110 & 70,5 \\
\hline \multirow{3}{*}{$\begin{array}{c}\text { Raça/cor que ACS } \\
\text { julga ter }(n=155)\end{array}$} & Preta & 25 & 16 \\
\hline & Parda & 100 & 64,1 \\
\hline & Branca & 30 & 19,2 \\
\hline \multirow{2}{*}{ Gênero (n=156) } & Masculino & 13 & 8,3 \\
\hline & Feminino & 143 & 91,7 \\
\hline \multirow{6}{*}{$\begin{array}{c}\text { Grau de instrução } \\
\qquad(n=156)\end{array}$} & $\begin{array}{l}\text { Fundamental } \\
\text { Incompleto }\end{array}$ & 2 & 1,3 \\
\hline & $\begin{array}{c}\text { Fundamental } \\
\text { Completo }\end{array}$ & 1 & 0,6 \\
\hline & Médio Incompleto & 9 & 5,8 \\
\hline & Médio Completo & 109 & 69,9 \\
\hline & Superior Incompleto & 17 & 10,9 \\
\hline & Superior Completo & 18 & 11,5 \\
\hline \multirow{4}{*}{$\begin{array}{l}\text { Consegue realizar } \\
\text { visita domiciliar } \\
\text { mensal a todas as } \\
\text { famílias }(n=156)\end{array}$} & Sempre & 4 & 2,6 \\
\hline & Frequentemente & 24 & 15,4 \\
\hline & Raramente & 51 & 32,7 \\
\hline & Nunca & 77 & 49,4 \\
\hline
\end{tabular}

A Tabela 2 evidencia que $96,2 \%$ dos ACS foram incentivados a preocupar-se com questões de saúde bucal da comunidade. Grande número desses profissionais $(86,5 \%)$ fez curso introdutório para atuar como ACS 
e $73,1 \%$ dos que participaram avaliaram esse momento educativo e informativo como satisfatório. Porém, $73,1 \%$ dos participantes desse treinamento não foram incentivados sobre as questões de saúde bucal e os traumatismos dentários.

A participação em grupos educativos de saúde bucal prevalece em $89,7 \%$ dos profissionais. A maioria dos entrevistados mantémo grupo há mais de quatro anos $(71,8 \%)$. Muitos grupos educativos de saúde bucal são liderados pelo Cirurgião Dentista (85,9\%). Em relação ao grau de satisfação desses grupos, $54,2 \%$ classificam-se como satisfatório. Entre os temas trabalhados nos grupos de saúde bucal, não consta a temática "traumatismos dentários" para $62,2 \%$ dos participantes. Os dados estão ilustrados na Tabela 2.

Tabela 2. Expectativas/satisfação dos Agentes Comunitários de Saúde no trabalho da Atenção Básica e cuidados de saúde bucal.

\begin{tabular}{|c|c|c|c|}
\hline \multicolumn{2}{|l|}{ Variáveis } & \multirow{2}{*}{$\begin{array}{l}\text { N. } \\
150\end{array}$} & \multirow{2}{*}{$\begin{array}{c}\% \\
96,2\end{array}$} \\
\hline $\begin{array}{c}\text { Foi incentivado a } \\
\text { preocupar-se com } \\
\text { questões de saúde bucal }\end{array}$ & Sim & & \\
\hline $\begin{array}{l}\text { o tempo de trabalho na } \\
\text { Atenção Básica? }(n=156)\end{array}$ & Não & 6 & 3,8 \\
\hline \multirow{2}{*}{$\begin{array}{l}\text { Fez curso introdutório } \\
\text { para atuar nessa unidade } \\
\text { de saúde? }(n=156)\end{array}$} & Sim & 135 & 86,5 \\
\hline & Não & 21 & 13,5 \\
\hline \multirow{3}{*}{$\begin{array}{l}\text { Como você classifica } \\
\text { esse curso introdutório? } \\
\qquad(n=135)\end{array}$} & Satisfatório & 114 & 73,1 \\
\hline & $\begin{array}{c}\text { Pouco } \\
\text { satisfatório }\end{array}$ & 20 & 12,8 \\
\hline & Insatisfatório & 1 & 0,6 \\
\hline \multirow{2}{*}{$\begin{array}{l}\text { O curso introdutório } \\
\text { incentivou a preocupar-se } \\
\text { com questões de saúde } \\
\text { bucal em especial sobre } \\
\text { traumatismo dentário? } \\
(n=135)\end{array}$} & Sim & 21 & 13,5 \\
\hline & Não & 114 & 73,1 \\
\hline \multirow{2}{*}{$\begin{array}{l}\text { Participa de grupos } \\
\text { educativos de saúde } \\
\text { bucal? }(n=156)\end{array}$} & Sim & 140 & 89,7 \\
\hline & Não & 16 & 10,3 \\
\hline \multirow{4}{*}{$\begin{array}{l}\text { Há quanto tempo você } \\
\text { participa deste grupo? } \\
\qquad(n=140)\end{array}$} & $<6$ meses & 1 & 0,6 \\
\hline & $\begin{array}{c}6 \text { meses a } 2 \\
\text { anos }\end{array}$ & 14 & 9,0 \\
\hline & 2 a 4 anos & 13 & 8,3 \\
\hline & $>4$ anos & 112 & 71,8 \\
\hline
\end{tabular}

\begin{tabular}{|c|c|c|c|}
\hline \multirow{4}{*}{$\begin{array}{l}\text { Qual profissional lidera } \\
\text { esse grupo? }(n=140)\end{array}$} & $C D$ & 134 & 85,9 \\
\hline & ASB & 1 & 0,6 \\
\hline & ACS & 4 & 2,6 \\
\hline & Outros & 1 & 0,6 \\
\hline \multirow{4}{*}{$\begin{array}{l}\text { Como você classifica } \\
\text { esse grupo? }(n=140)\end{array}$} & $\begin{array}{c}\text { Muito } \\
\text { Satisfatório }\end{array}$ & 25 & 16,0 \\
\hline & Satisfatório & 85 & 54,5 \\
\hline & $\begin{array}{c}\text { Pouco } \\
\text { Satisfatório }\end{array}$ & 28 & 17,9 \\
\hline & Insatisfatório & 2 & 1,3 \\
\hline \multirow{2}{*}{$\begin{array}{c}\text { Nesse grupo foi } \\
\text { trabalhado o tema } \\
\text { traumatismo dentário? } \\
(n=138)\end{array}$} & Sim & 41 & 26,3 \\
\hline & Não & 97 & 62,2 \\
\hline \multirow{4}{*}{$\begin{array}{c}\text { Em relação ao seu } \\
\text { trabalho na Atenção } \\
\text { Básica, você julga que: } \\
(n=156)\end{array}$} & $\begin{array}{l}\text { Sempre esteve } \\
\text { em meus planos }\end{array}$ & 42 & 26,9 \\
\hline & $\begin{array}{l}\text { Não estava nos } \\
\text { meus planos, } \\
\text { mas atualmente } \\
\text { pretendo } \\
\text { permanecer no } \\
\text { meu trabalho } \\
\end{array}$ & 96 & 61,5 \\
\hline & $\begin{array}{c}\text { É algo } \\
\text { passageiro até } \\
\text { encontrar algo } \\
\text { melhor }\end{array}$ & 14 & 9,0 \\
\hline & $\begin{array}{c}\text { Embora } \\
\text { não tivesse } \\
\text { interesse, } \\
\text { não tive outra } \\
\text { oportunidade }\end{array}$ & 4 & 2,6 \\
\hline \multirow{4}{*}{$\begin{array}{l}\text { Quanto à satisfação } \\
\text { atual com o trabalho na } \\
\text { Atenção Básica, você } \\
\text { julga que está: ( } n=156)\end{array}$} & Muito Satisfeito & 20 & 12,8 \\
\hline & Satisfeito & 84 & 53,8 \\
\hline & Pouco Satisfeito & 47 & 30,1 \\
\hline & Insatisfeito & 5 & 3,2 \\
\hline \multirow{3}{*}{$\begin{array}{l}\text { Quanto à satisfação em } \\
\text { relação ao cuidado de } \\
\text { saúde bucal com sua } \\
\text { microárea: }(n=155)\end{array}$} & $\begin{array}{l}\text { Sinto-me } \\
\text { satisfeito }\end{array}$ & 68 & 43,6 \\
\hline & $\begin{array}{c}\text { Sou indiferente } \\
\text { e apenas realizo } \\
\text { meu trabalho }\end{array}$ & 22 & 14,1 \\
\hline & $\begin{array}{c}\text { Sinto-me } \\
\text { insatisfeito, mas } \\
\text { preciso fazê-lo }\end{array}$ & 65 & 41,7 \\
\hline \multirow{4}{*}{$\begin{array}{l}\text { Como você autoavalia } \\
\text { seu desempenho no } \\
\text { cuidado de saúde bucal } \\
\text { com a população: }(n=156)\end{array}$} & $\begin{array}{c}\text { Muito } \\
\text { Satisfatório }\end{array}$ & 8 & 5,1 \\
\hline & Satisfatório & 86 & 55,1 \\
\hline & $\begin{array}{c}\text { Pouco } \\
\text { Satisfatório }\end{array}$ & 54 & 34,6 \\
\hline & Insatisfatório & 8 & 5,1 \\
\hline
\end{tabular}


Quanto ao trabalho dos ACS na atenção básica, muitos dos profissionais julgam que esse ofício não estava em seus planos, mas pretendem permanecer atuando (61,5\%) e a minoria não tinha interesse de trabalhar nessa profissão e eles atuam por não ter outra oportunidade (2,6\%). Ademais, os ACS estão satisfeitos com o seu trabalho na atenção básica $(53,8 \%)$. Em relação à satisfação dos ACS quanto à realização dos cuidados de saúde bucal com a população da micro área onde atuam, 43,6\% estão satisfeitos. Entretanto, a autoavaliação desses profissionais quanto ao seu desempenho nos cuidados de saúde bucal com a comunidade mostra que 5,1\% acham seu desempenho muito satisfatório, apesar de lhes faltar conhecimento específico quanto ao item traumatismo dentário. Os dados estão ilustrados na Tabela 2.

Em relação aos conhecimentos dos ACS sobre os traumatismos dentários, $64,1 \%$ dos profissionais nunca participaram de qualquer palestra sobre o tema. Dos $35,3 \%$ que já participaram, a minoria conseguiu participar de mais de quatro palestras $(4,5 \%)$. Dos conhecimentos adquiridos nesses eventos, $11,5 \%$ dos profissionais estão amplamente seguros para orientar a micro área de abrangência (Tabela 3).

Quando se investigou a atitude dos ACS diante do paciente com traumatismo dentário, verificou-se que $81,4 \%$ não utilizam qualquer protocolo para o atendimento. Além disso, $75,0 \%$ dos profissionais revelaram que não existe um fluxograma de atendimento na unidade de saúde para auxiliar o paciente com traumatismo dentário. A orientação dos ACS em casos de traumatismos dentários foi para o paciente procurar o Cirurgião-Dentista na unidade de saúde o mais rápido possível (86,5\%) (Tabela 4).

Em relação aos conhecimentos dos ACS sobre o agravo "avulsão dentária", 76,3\% afirmaram que somente o Cirurgião-Dentista
Tabela 3. Conhecimentos dos ACS sobre traumatismos dentários no contexto geral.

\begin{tabular}{c|c|c|c}
\hline Variáveis & N. & $\%$ \\
\hline $\begin{array}{c}\text { Participou de } \\
\text { palestra sobre } \\
\text { traumatismo } \\
\text { dentário? (n=155) }\end{array}$ & Sim & 55 & 35,3 \\
\cline { 2 - 4 } & Una & 100 & 64,1 \\
\hline \multirow{2}{*}{$\begin{array}{c}\text { Participou de } \\
\text { quantas palestras } \\
\text { sobre traumatismo } \\
\text { dentário? (n=56) }\end{array}$} & Duas & 16 & 10,3 \\
\cline { 2 - 4 } & Entre duas e quatro & 17 & 10,3 \\
\hline \multirow{2}{*}{$\begin{array}{c}\text { Conhecimentos } \\
\text { adquiridos nessas } \\
\text { palestras tornaram } \\
\text { você seguro } \\
\text { para orientar a }\end{array}$} & Sim, amplamente & 18 & 11,5 \\
\cline { 2 - 4 } população? (n=56) & Sim, parcialmente & 36 & 23,1 \\
\cline { 2 - 4 } & Não & 2 & 1,3 \\
\hline \multirow{2}{*}{$\begin{array}{c}\text { Quem ministrou as } \\
\text { palestras? (n=56) }\end{array}$} & ESB (CD, ASB, TSB) & 4 & 2,6 \\
\cline { 2 - 4 } & Médico/Enfermeiro & 2 & 1,3 \\
\cline { 2 - 4 } & Outros & 2 & 1,3 \\
\hline
\end{tabular}

poderia realizar o reimplante do dente. Já em relação à atitude do ACS diante da situação, $9,0 \%$ responderam que não saberiam o que fazer por não ter treinamento algum. Quanto ao meio de armazenamento do dente, $28,8 \%$ dos profissionais não saberiam o que fazer com o dente diante dessa situação, enquanto $16,0 \%$ responderam que armazenariam em leite (Tabela 4).

Em casos de fratura dentária, houve também os profissionais que acreditam que o fragmento não teria mais utilidade e pediriam para jogar fora $(5,8 \%)$ e $12,8 \%$ guardariam o fragmento. Dos entrevistados, 98,1\% acham importante ter os conhecimentos sobre esse tema para orientar a população e desenvolver atividades educativas a respeito do traumatismo dentário para a equipe de saúde e para a comunidade (Tabela 4). 
Tabela 4. Atitudes do ACS frente aos traumatismos dentários.

\begin{tabular}{|c|c|c|c|}
\hline \multicolumn{2}{|l|}{ Variáveis } & N. & $\%$ \\
\hline \multirow{2}{*}{$\begin{array}{l}\text { Utiliza algum protocolo de traumatismo dentário } \\
\text { para a população de sua microárea? }(n=156)\end{array}$} & Sim & 29 & 18,6 \\
\hline & Não & 127 & 81,4 \\
\hline \multirow{3}{*}{$\begin{array}{c}\text { Existe fluxograma de atendimento na unidade } \\
\text { de saúde onde você trabalha para que você } \\
\text { possa orientar o paciente com traumatismo } \\
\text { dentário? }(n=156)\end{array}$} & Sim & 17 & 10,9 \\
\hline & Não & 117 & 75,0 \\
\hline & Não sei informar & 22 & 14,1 \\
\hline \multirow{3}{*}{$\begin{array}{l}\text { O que faria para orientar um paciente em caso } \\
\text { de traumatismo dentário? }(n=156)\end{array}$} & $\begin{array}{l}\text { Procurar o CD na unidade de saúde o mais } \\
\text { rápido possível }\end{array}$ & 135 & 86,5 \\
\hline & $\begin{array}{l}\text { Levaria o caso para a equipe e agendaria } \\
\text { uma consulta }\end{array}$ & 20 & 21,8 \\
\hline & Não sei como orientar & 1 & 0,6 \\
\hline \multirow{4}{*}{$\begin{array}{c}\text { Em relação à avulsão dentária, em caso } \\
\text { de reimplante, quem poderia fazer esse } \\
\text { procedimento? }(n=156)\end{array}$} & Eu mesmo & 13 & 8,3 \\
\hline & Profissional de saúde de nível superior & 16 & 10,3 \\
\hline & Somente o CD & 119 & 76,3 \\
\hline & Não sei & 8 & 5,1 \\
\hline \multirow{3}{*}{$\begin{array}{l}\text { Em relação à avulsão dentária, qual seria a sua } \\
\text { orientação na microárea? }(n=156)\end{array}$} & $\begin{array}{l}\text { Eu reimplantaria o dente o mais rápido } \\
\text { possível }\end{array}$ & 10 & 6,4 \\
\hline & $\begin{array}{l}\text { Procurar o } C D \text { na unidade de saúde o mais } \\
\text { rápido possível }\end{array}$ & 32 & 84,6 \\
\hline & Não sei o que faria, pois não tive treinamento & 14 & 9,0 \\
\hline \multirow{8}{*}{$\begin{array}{c}\text { Em relação à avulsão dentária, qual o melhor } \\
\text { meio de armazenamento que você considera } \\
\text { para colocar o dente até o paciente procurar o } \\
\text { CD? }(n=156)\end{array}$} & Água filtrada e fervida & 39 & 25,0 \\
\hline & Álcool & 14 & 9,0 \\
\hline & Leite & 25 & 16,0 \\
\hline & Soro & 28 & 17,9 \\
\hline & Não sei & 45 & 28,8 \\
\hline & Frasco estéril & 1 & 0,6 \\
\hline & Gelo & 1 & 0,6 \\
\hline & Saliva & 3 & 1,9 \\
\hline \multirow{4}{*}{$\begin{array}{c}\text { Em caso de traumatismo dentário, onde o } \\
\text { paciente tenha fragmento do dente na mão, o } \\
\text { que faria? }(n=156)\end{array}$} & Procurar CD na unidade mais rápido possível & 118 & 75,6 \\
\hline & $\begin{array}{c}\text { Jogar fora o fragmento do dente, pois não } \\
\text { tem utilidade }\end{array}$ & 9 & 5,8 \\
\hline & Guardar o pedaço do dente & 20 & 12,8 \\
\hline & Não sei & 8 & 5,1 \\
\hline \multirow{3}{*}{$\begin{array}{c}\text { Acha importante ter conhecimento sobre } \\
\text { traumatismos dentários para orientar a } \\
\text { população? ( } \mathrm{n=156)}\end{array}$} & Com certeza & 153 & 98,1 \\
\hline & Parcialmente & 1 & 0,6 \\
\hline & Não sei & 1 & 0,6 \\
\hline \multirow{2}{*}{$\begin{array}{c}\text { Acha importante a equipe de saúde bucal, } \\
\text { onde você trabalha, desenvolver atividades } \\
\text { de educação em saúde sobre traumatismos } \\
\text { dentários para todos os profissionais da equipe } \\
\text { e comunidade? }(\mathrm{n}=156)\end{array}$} & Com certeza & 153 & 98,1 \\
\hline & Parcialmente & 2 & 1,3 \\
\hline
\end{tabular}




\section{Dıscussão}

Entre os agravos de saúde bucal, no Brasil, destacam-se os traumatismos dentários (TD) principalmente devido à sua alta prevalência e gravidade. É considerado pela Organização Mundial da Saúde (OMS) um problema de saúde pública, onde existem medidas de prevenção e geram alto custo e impacto. ${ }^{10}$ Portanto, torna-se relevante este estudo que avaliou o conhecimento dos Agentes Comunitários de Saúde (ACS) na zona urbana do município de Vitória da Conquista (BA) frente aos traumatismos dentários.

Os achados predominantes deste estudo expressam a alarmante realidade da população quando se trata do pronto atendimento frente aos TD. Isso se deve à falta de informações e orientações transmitidas para a comunidade, que na maioria das vezes não sabe como proceder frente a uma urgência odontológica e com isso poderá contribuir para prognósticos desfavoráveis e até mesmo perdas de elementos dentários. Convém salientar que o comprometimento estético consequente dos traumas dentários influenciam diretamente no convívio social, o que pode gerar impactos psicológicos principalmente em indivíduos jovens que prezam o padrão de beleza dito pela sociedade, no qual o sorriso está inserido. ${ }^{11}$

O TD é um agravo importante que tem uma inter-relação familiar, socioeconômica e cultural da comunidade. Portanto, torna-se relevante que o TD seja abordado nos serviços de saúde pública e privada e com destaque aos ACS no âmbito da atenção básica com ênfase na Estratégia de Saúde da Família (ESF). ${ }^{12}$ Nesse contexto, o ACS entra como peça-chave, visto que esse profissional reside na microárea onde presta assistência às famílias, vivencia a realidade local e tem contato direto com os usuários do Sistema Único de Saúde (SUS), contribuindo para o estabelecimento do vínculo. ${ }^{11}$ Este estudo investigou o conheci- mento dos ACS que seriam os multiplicadores do processo de educação em saúde bucal com foco nos TD.

Para tanto, é relevante que os ACS tenham um bom nível de escolaridade, como registrado neste estudo, que facilite o entendimento dos assuntos abordados ao longo de sua atuação na atenção básica, mas que tenham também o compromisso e responsabilidade dos gestores do SUS em investimentos no processo de educação permanente desses profissionais. Pois, uma escolaridade fragilizada associada a uma falta de regularidade em capacitação dos profissionais sobre a saúde bucal poderá acarretar um prejuízo muito grande para a comunidade assistida. ${ }^{12}$

Da mesma forma, o curso introdutório é uma importante estratégia para orientá-los no início de suas atividades laborais, o que reforça sua mudança de prática assistencial pautadas no modelo biomédico e hegemônico, e então alcançar os objetivos propostos pela ESF. ${ }^{13,14}$ No entanto, os resultados deste estudo revelaram que a grande maioria participou dos treinamentos introdutórios, porém temas como saúde bucal e em destaque os TD não foram abordados. Para isso, cabe aos idealizadores a tarefa de rever os métodos aplicados nesse treinamento, almejando uma maior eficácia e que questões de saúde bucal possam também serem abordadas para toda a equipe de saúde.

Do mesmo modo, a maioria dos ACS participa de grupos educativos de saúde bucal, criados pelos próprios profissionais das unidades de saúde, que são momentos de atividades educativas e coletivas em espaços sociais como escolas, creches, associações de bairros e igrejas, para transmissão de informações, porém não abordam nesses momentos o tema TD, perdendo a oportunidade de possibilitar o acesso à informação nos grupos de escolares que estão mais vulneráveis. Enquanto estudos relataram ${ }^{1,14,15}$ que a fase mais propensa para o 
TD seria nas idades dos escolares, como relatado no estudo de Frujeri, ${ }^{14}$ que muitos dos incidentes ocorreram aos 10 anos de idade, sendo constituída a queda o principal fator etiológico, seguido de colisões com objetos ou pessoas.

Em relação à participação dos ACS em palestras, os resultados deste estudo mostraram baixa participação, sendo pouco abordado o TD. Portanto, a maioria também revelou insegurança para orientar a comunidade. Como o Cirurgião Dentista (CD) está inserido na ESF e o estudo evidenciou que são os profissionais que lideram a maioria dos grupos de saúde bucal, sugere-se que a sensibilização e a transmissão de informações partam desses profissionais, que podem organizar o cronograma de trabalho para instruí-los, na tentativa de facilitar o acesso à informação. Assim, a abordagem do tema na comunidade será facilitada. Pois, a educação permanente em saúde deve ser proporcionada, para que os ACS tenham novas concepções do seu trabalho diário, tornando sua trajetória profissional mais prazerosa. ${ }^{16}$

No estudo de Lopes, ${ }^{17}$ os ACS relataram que sentem satisfação com o trabalho em parceria com outros agentes, por compartilharem as dificuldades da profissão tendo ajuda recíproca. Neste estudo, os ACS estão satisfeitos com sua profissão, porém essa função não estava nos planos da maioria deles, mas mesmo assim eles pretendem permanecer no seu trabalho. A qualidade nas atividades realizadas pelos ACS, a capacidade de interagir, observar e conhecer as pessoas de sua área definem sua satisfação. ${ }^{18}$ No entanto, a satisfação apontada nas investigações comprova que a realização profissional se mostra uma questão singular e abstrata. ${ }^{17}$ Entretanto, torna-se importante a realização dos ACS com seu trabalho, para que isso de certa forma possa influenciar positivamente na sua atuação profissional.

Quando se refere ao TD, antes de qualquer procedimento é necessário acalmar as vítimas e/ou responsáveis para conseguir realizar o pronto atendimento o mais rápido possível. A maioria dos ACS não utiliza qualquer protocolo de atendimento para o TD e a conduta não segue o que é preconizado, coincidindo com as atitudes dos investigados do estudo de Piva, ${ }^{4}$ que foi encaminhar para o CD da unidade de saúde imediatamente e os demais nem saberiam como orientar, certificando-se que esses profissionais não estão aptos para socorrer uma vítima. Mas, o atendimento de urgência é o que garante um prognóstico melhor, evitando que ocorra necrose pulpar ou até mesmo perda do elemento dentário. ${ }^{4}$ Com isso, é prudente que os ACS diante do TD saibam distinguir as diferentes situações e orientar a comunidade de uma forma correta a ser adotada para minimizar os possíveis danos. ${ }^{19}$

Nos casos de avulsão dentária, é importante que os ACS saibam da importância do reimplante imediato até os primeiros 30 minutos, pois o período entre a avulsão do dente e o seu reimplante interfere diretamente no prognóstico. ${ }^{20,21}$ Questionados sobre essa conduta, verificou-se que apenas $8,3 \%$ dos ACS fariam o reimplante imediato, um dado preocupante, pois se sabe que qualquer profissional ou pessoa com treinamento adequado pode realizar tal procedimento. ${ }^{22}$ Somente $76,3 \%$ afirmaram que o CD poderia realizar o reimplante dentário, demonstrando a falta de conhecimento desses profissionais sobre as manobras adequadas no pronto atendimento. Uma vez rompidas as células do ligamento periodontal, no decorrer do tempo ocorre necrose dessas células rapidamente e o percentual de sucesso diminui drasticamente. ${ }^{23,24}$

Estudos revelaram ${ }^{24,25,} 26$ que a solução salina balanceada de Hank é considerada o melhor meio para armazenamento de dentes, seguido do leite que apresenta em suas propriedades fisiológicas $\mathrm{pH}$ entre 6,5 e 7,2, osmolaridade similar aos fluídos extracelulares e presença de substâncias nutricionais que 
mantêm a vitalidade das células do ligamento periodontal, além de ser relativamente livre de bactérias e de fácil acesso, entretanto, apenas $16 \%$ dos investigados deste estudo armazenariam em leite e a maioria não soube informar qual o meio de armazenamento preconizado para acondicionar o dente $\mathrm{e}$ transportá-lo até o CD. Além disso, a saliva foi citada por $1,9 \%$ dos investigados, um meio de armazenamento considerado inadequado devido ao curto tempo para o reimplante e a presença de microrganismos que favorecem a contaminação das células do ligamento periodontal, bem como, infecção cruzada. ${ }^{25}$ Os dados retratam a falta de informação dos ACS sobre os meios de armazenamento, dificultando dessa forma o prognóstico e diminuindo a chance de manutenção do dente na arcada dentária.

Do mesmo modo, o dente fraturado depende da profundidade de envolvimento dos tecidos dentários para o tratamento, tendo a possibilidade de colagem do fragmento dentário. ${ }^{20}$ Porém, quando se questionou a atitude do ACS diante da fratura dentária, a minoria pediria para armazenar o fragmento para ser utilizado posteriormente e $5,1 \%$ dos ACS não saberiam como orientar o paciente o que torna preocupante, já que o conhecimento dos ACS sobre o assunto pode influenciar no prognóstico do caso clínico.

Observou-se no estudo de Mialhe ${ }^{27}$ que os ACS podem contribuir na promoção de saúde bucal, desde que haja o investimento contínuo no processo de educação permanente desses profissionais, tendo base nos indicadores epidemiológicos, além de sensibilizá-los da importância de suas práticas preventivas e assistenciais. Dessa forma, fica evidente a necessidade de estudos futuros e ressaltar que não existem, na literatura brasileira, pesquisas que abordam o conhecimento dos ACS frente aos traumatismos dentários. Além disso, é prudente e necessário divulgar os resultados desta pesquisa aos gestores e até mesmo para os próprios ACS, com o objetivo de esclarecimento desses profissionais, visando ainda mais a melhoria nas prestações de serviços ofertadas para a comunidade. Os dados obtidos neste estudo foram autodeclarados pelos participantes e, portanto, é necessária cautela na interpretação de alguns dados divulgados nesta pesquisa.

\section{Considerações finAIS}

Diante dos resultados aqui apresentados e discutidos, é plausível concluir que a maioria dos ACS investigados não tem conhecimentos sobre os traumatismos dentários e eles não se sentem seguros para promover educação em saúde bucal com ênfase nessa temática na comunidade, e ainda não estão preparados para realizar condutas adequadas no pronto atendimento. O bom nível de escolaridade desses profissionais facilita a absorção de conhecimentos adquiridos, portanto, tornase necessário um processo de educação permanente com capacitações e sensibilização dos ACS, com os demais membros da equipe, na busca da integralidade do atendimento e promoção de saúde bucal, assegurando dessa forma uma assistência integral e humanizada com prognósticos favoráveis, para um pronto atendimento adequado e seguro. Contudo, a minoria dos ACS consegue realizar visita domiciliar mensal a todas as famílias, o que dificulta o acesso à informação para parte da comunidade. No entanto, é imprescindível que os Cirurgiões-Dentistas introduzam no seu cronograma de trabalho a abordagem de temas de saúde bucal com os ACS para um fácil acesso à informação desses profissionais, inclusive os traumatismos dentários, para que eles possam orientar a comunidade com condutas efetivas. 


\section{REFERÊNCIAS}

1. Blackwell M. Epidemiology of traumatic dental injuries - a 12 year review of the literature. Dent traumatol. 2008, 24: 603-11.

https://doi.org/10.1111/j.16009657.2008.00696.x

2. Brasil. Ministério da Saúde. Secretaria de Atenção à Saúde. Secretaria de Vigilância em Saúde. SB Brasil 2010: Pesquisa Nacional de Saúde Bucal: resultados principais. Ministério da Saúde. Brasília, DF; 2012.

http://bvsms.saude.gov.br/bvs/publicacoes/ pesquisa_nacional_saude_bucal.pdf

3. Roncalli AG, Silva NN, Nascimento AC, Freitas CHSM, Casotti E., Peres GK, et al. Aspectos metodológicos do Projeto SBBrasil 2010 de interesse para inquéritos nacionais de saúde. Cad Saúde Públic. 2012, 28: 540-57.

http:/dx.doi.org/10.1590/S0102 $-311 X 2012001300006$

4. Piva F., Potter IG, Sari GT, Júnior CAK, Souza FHC. Atendimento de urgência frente ao traumatismo alvéolo dentário - relato de caso clínico. Rev Assoc Paul Cir Dent. 2013, 67 (4): 224-9.

http://revodonto.bvsalud.org/pdf/apcd/v67n4/ a05v67n4.pdf

5. Frazão P., Marques D. Efetividade de programa de agentes comunitários na promoção da saúde bucal. Rev de Saúde Púb. 2009, 43 (3): 463-71.

http://www.scielo.br/pdf/rsp/v43n3/85.pdf

6. Santos KT, Saliba NA, Moimaz SAS, Arcieri MR, Carvalho ML. Agente comunitário de saúde: perfil adequado a realidade do Programa Saúde da Família? Ciên e Saúde Colet. 2011, 16 (1): 1.023-8. http://www.scielo.br/pdf/csc/v16s1/a35v16s1.pdf

7. Machado LM, Mattos KM, Colomé JS, Freitas $N Q$, Sangoi TP. Estratégia saúde da família: A percepção do agente comunitário de saúde quanto a sua atuação. Cien Cuid Saúde. 2015, 1.105-12.

http://www.periodicos.uem.br/ojs/index.php/ CiencCuidSaude/article/view/22612/pdf_360

8. Brasil. Ministério do Planejamento, Orçamento e Gestão. Instituto Brasileiro de Geografia e Estatística. Censo demográfico, 2017. https://ww2.ibge.gov.br/home/estatistica/populacao/estimativa2017/estimativa_dou.shtm

9. Miot HA. Tamanho da amostra em estudos clínicos e experimentais. J Vasc Bras. 2011,10 (4): 275-8. http://www.scielo.br/pdf/jvb/v10n4/v10n4a01.pdf

10. Rodrigues AS, Castilho T., Antunes LAA, Antunes LS. Perfil Epidemiológico dos Traumatismos Dentários em Crianças e Adolescentes no Brasil Epidemiological Profile of Dental Trauma in Children and Adolescents in Brazil. Cient Ciên Biol Saúd. 2015, 17 (4): 267-78.

http://www.pgsskroton.com.br/seer/index.php/ JHealthSci/article/viewFile/3270/3001

11. Santos V., Seabra S., Chevitarese L. Traumatismo dentário numa visão para a promoção de saúde. Saúde \& Amb Rev. 2010, 5 (1): 1-7. http://publicacoes.unigranrio.edu.br/index.php/ sare/article/view/1093/681

12. Pires ROM, Neto FN, Lopes JB, Bueno SMV. O conhecimento dos agentes comunitários sobre saúde bucal: uma perspectiva sobre deficiências em educação em saúde no PSF. Ciên Cuid Saúd. 2007, jul./set. 6 (3): 325-34. http://eduem.uem.br/ojs/index.php/CiencCuidSaude/article/viewFile/3993/2714

13. Brasil. Treinamento introdutório. Ministério da Saúde. Secretaria de Políticas de Saúde Departamento de Atenção Básica. Brasília, DF, 2000. http://bvsms.saude.gov.br/bvs/publicacoes/cad02 treinamento.pdf

14. Frujeri MLV, Frujeri JAJ, Bezerra ACB, Cortes MISG, Junior EC. Socio-economic indicators and predisposing factors associated with traumatic dental injuries in schoolchildren at Brasília, Brazil: a cross-sectional, population-based study. Oral Health. 2014, 14 (91): 1-7. https://doi.org/10.1186/1472-6831-14-91

15. Bezerra PKM, Cavalcante AL, Alencar CRB. Maloclusões e traumatismos dentários em escolares de seis a doze anos de idade: estudo piloto. UFES Rev Odontol. 2007, jan./abr. 9 (1): 26-32.

http://periodicos.ufes.br/RBPS/article/viewFile/625/431

16. Koyashiki GAK, Souza RAA, Garanhani ML. O trabalho em saúde bucal do Agente Comunitário de Saúde em Unidades de Saúde da Famí- 
lia. Ciên \& Saú Colet. 2008, 13 (4): 1.343-54. http://www.scielo.br/pdf/csc/v13n4/32.pdf

17. Lopes DMQ, Beck CLC, Prestes FC, Weiller TH, Colomé JS, Silva GM. Agentes Comunitários de Saúde e as vivências de prazer - sofrimento no trabalho: estudo qualitativo. Rev Esc Enferm USP. 2012, 46 (3): 633-40.

http://www.revistas.usp.br/reeusp/article/ viewFile/40991/44518

18. Santos AM, Assis MMA, Nascimento MAA, Jorge MSB. Vínculo e autonomia na prática de saúde bucal no Programa Saúde da Família. Rev Saúd Públ. 2008, 42 (3): 464-70. https://repositorio.ufba.br/ri/bitstream/ ri/2190/1/6189.pdf

19. Sanabe ME, Cavalcante LZ, Coldebellas CR, Lima FCBA. Urgências em traumatismos dentários: classificação, características e procedimentos. Rev Paul Pediatr. 2009, 27 (4): 447-51. http://www.scielo.br/pdf/rpp/v27n4/v27n4a15.pdf

20. Costa LED, Queiroz FS, Nóbrega CBC, Leite MS, Nóbrega WFS, Almeida ER. Trauma dentário na infância: avaliação da conduta dos educadores de creches públicas de Patos-PB. Rev Odontol UNESP. 2014, nov./dez. 43 (6): 402-8. http://www.scielo.br/pdf/rounesp/ v43n6/1807-2577-rounesp-43-06-0402.pdf

21. Sousa MH, Westphalen VPD, Santos CR. Reimplante dentário bem-sucedido complicado por novo traumatismo alvéolo-dentário. Rev de Clín Pesq Odontol. 2005, jul./set. 2 (1): 61-6. www 2.pucpr.br/reol/index.ph p/ aor?dd1 $=36 \& d d 2=52 \& d d 3=\& d d 99=p d f$

22. Costa AJM, Lasserre FS, Westphalen VPD, Deonizio MDA, Neto UXS, Sousa MH. Reimplante dentário tardio: Relato de caso clínico. Rev de Clín Pesq Odontol. 2004, out./dez. 1 (2): 41-3.

https://periodicos.pucpr.br/index.php/oralresearch/article/view/22828/21932

23. Victorino FR, Gottardo VD, Junior RZ, Moreschi E., Zamponi M., Trento CL. Reimplante dentá- rio para o tratamento de Avulsão Dentária: relato de caso clínico. Rev Assoc Paul Cir Dent. 2013, 67 (3): 202-6.

http://revodonto.bvsalud.

org/scielo.php?pid=S0004-

$-52762013000400006 \&$ script=sci_ arttext\&tlng=pt

24. Monteiro JES, Sousa RV, Firmino RT, Garcia AFG, Ferreira JMS, Menezes VA. Conhecimento de acadêmicos de Educação Física sobre a avulsão e o reimplante dentário. Rev da Facul de Odontol. 2012, mai./ago. 17 (2): 131-6.

http://revodonto.bvsalud.

org/scielo.php?pid=S1413-

$-40122012000200002 \&$ script $=$ sci_ arttext\&tlng $=\mathrm{pt}$

25. Rodrigues TLC, Rodrigues FG, Rocha JF. Avulsão dentária: Proposta de tratamento e revisão da literatura. Rev Odontol Univ Cidad SP. 2010, mai./ago. 22 (2): 147-53.

http://arquivos.cruzeirodosuleducacional.edu.br/ principal/old/revista_odontologia/pdf/maio_ agosto_2010/unicid_22_02_147_53.pdf

26. Santos AF, Silva NB, Cardoso AMR, Xavier AFC. Perspectiva dos professores de educação física da rede pública sobre condutas emergenciais em avulsões dentárias. Temas em Saúd. 2017, 17 (2): 22-38.

http://dspace.bc.uepb.edu.br/jspui/handle/123456789/8079

27. Mialhe FL, Lefèvre F., Lefèvre AMC. O agente comunitário de saúde e suas práticas educativas em saúde bucal: uma avaliação qualiquantitativa. Ciên \& Saúd Colet. 2011; 16 (11): 4.425-32.

https://www.scielosp.org/article/ssm/content/ raw/?resource_ssm_path=/media/assets/csc/ v16n11/a15v16n11.pdf

Submetido em: 25-11-2017

Aceito em: 15-5-2018 